\title{
Neurociência e mística: Existe uma possibilidade para pensar Deus?
}

Neuroscience and Mysticism: There is a possibility to think God?

Resumo: $\mathrm{O}$ artigo apresenta brevemente as principais teses referentes à relação mente e cérebro no contexto dos emergentismos forte e fraco. Especificam-se ainda as principais consequências da discussão de uma possível neuroteologia para a compreensão dos processos de hominização, liberdade, limites do conhecimento cerebral e conhecimento do cérebro, relação entre mente-cérebro-mundo e "necessidade" do mistério gerada pela dinâmica cerebral.

Palavras-chave: Neuroteologia, Emergentismo, Mente, Cérebro, Neurociência.

Abstract: The article briefly presents the main theses regarding the mind and brain relationship in the context of strong and weak emergentisms. The main consequences of the discussion of a possible neurotheology for the understanding of the processes of hominization, freedom, limits of brain knowledge and knowledge of the brain, mind-brain-world relationship and "necessity" of the mystery generated by the brain dynamics.

Key words: Neurotheology, Emergentism, Mind, Brain, Neuroscience.

\section{[I]}

Conhece-te a ti mesmo (Gnôthi seautôn) - se a expressão não significa a vocação do ser humano, provavelmente retrata a maldição da inquietude humana fundamental. Todos os tempos e culturas revelam o embate humano na luta incessante pelo autoconhecimento. A humanidade, por vezes, evidencia uma proximidade enorme nessa busca, enquanto poucos passos adiante mergulha novamente na história obscura do seu passado. A arqueologia, a genética e a neurociência atuais traçam um caminho de aproximação e colaboração em vistas de conectar os elos históricos e genéticos da evolução humana. Nesse sentido, vivemos uma época de interdisciplinaridade que busca responder uma antiga questão -

\footnotetext{
${ }^{1}$ Doutor em Filosofia pela Pontifícia Universidade Católica do Rio Grande do Sul (PUCRS). Professor do Departamento de Filosofia e Ciências Sociais (DFICS) da Universidade Federal do Triângulo Mineiro (UFTM). Uberaba - MG - Brasil.
} 
o que é o homem? O autoconhecimento ou o reconhecimento da complexidade humana, quando não tomados pela maldição narcísica que termina no fascínio e na morte diante da própria beleza, propiciam uma aproximação demasiado sagaz do mistério que envolve o ser humano. Quer como imagem e semelhança da divindade quer como criatura pouco abaixo de Deus plasmada, coroada de glória e esplendor, o ser humano mira-se como fonte de fascínio e porta do mistério.

A arqueologia humana reconhece a humanidade como fonte de alguns mistérios ainda por serem estudados: "a nossa forma de andar, o bipedismo, a nossa forma de pensar, o nosso cérebro e a nossa forma de comunicar, a nossa linguagem articulada” (CUNHA, 2010, p. 144) distinguem-nos de todos os outros seres. O bipedismo, o pensamento e a linguagem permanecem, entretanto, como incógnitas na autocompreensão da humanidade. Mas essas incógnitas são precedidas por duas invariáveis biológicas ainda mais radicais: "de um lado, a origem dos primeiros sistemas vivos; do outro, o funcionamento do sistema mais intensamente teleonômico que jamais surgiu, isto é, o sistema nervoso central do homem" (MONOD, 2006, p. 137). O surgimento da vida e da inteligência constituem as extremidades do processo evolutivo que sequer o "ocaso" consegue explicar na perspectiva de Monod. Além disso, o povoamento do planeta revela uma verdadeira maravilha de conjunções teleonômicas da genética que também permanecem sem respostas definitivas. O povoamento das Américas, por exemplo, põe em xeque uma série de estudos e interpretações consistentemente documentados. Reconhece-se a complexidade desse povoamento através de três elementos: os fenótipos e genótipos, os rituais e a genética. O fenótipo de Luzia é tipicamente negroide, mas o ácido dexirribonucleico (ADN) mitocondrial é mongol. O que suscita a seguinte dúvida: a fusão das raças africana e mongol que deram origem aos "primeiros brasileiros" aconteceu antes ou depois da travessia do Estreito de Behring? Sabe-se que Luzia habitou as veredas mineiras, aproximadamente, entre treze a quinze mil anos antes do presente (AP), porém quais foram as mudanças genéticas ocorridas para termos a quinhentos anos AP uma população com fenótipo e genética distintos de Luzia? A ritualística necrológica datava de quatro mil AP considerando o México como a fonte do povoamento e da cultura americanas, entretanto as recentes descobertas comprovam ritos de decapitação altamente elaborados nas veredas mineiras a nove mil anos 
AP (STRAUSS et alii, 2015). O que atesta um povoamento anterior e, provavelmente, mais elaborado que o mexicano. Finalmente, a genética pré-colombiana distingue-se do período posterior atestando uma ruptura do elo genético do $\mathrm{ADN}$ mitocondrial dos povos originários, o que significa a existência de um hiato genético compreensível apenas mediante a consideração de um extermínio de noventa por cento da população précolombiana (LLAMAS et alii, 2016). Nesse sentido, desenvolvem-se os esforços da arqueologia, da genética evolutiva e da neurociência em vistas de estabelecerem os elos entre os hominóides (trinta e cinco milhões de anos AP) e a humanidade atual que continuamente busca o autoconhecimento. Frente a tamanhas invariáveis, para usar a expressão de Monod, as questões multiplicam e radicalizam-se em cada filão científico. Por isso, nos ateremos aos problemas introdutórios da neurociência.

A relação entre mente e cérebro pode ser entendida tanto como problema - algo passível de conhecimento futuro - ou como mistério questão que jamais alcançará esclarecimento pleno. Entre o problema e o mistério, enquanto formas elementares de equacionar a relação mentecérebro, estão as correntes do emergentismo forte (atestação da autonomia causal e das propriedades emergentes do cérebro, isto é, a fisiologia cerebral sobrepõe-se à mente e a compreensão dessa, reduz-se aos aspectos físicos) e emergentismo fraco (reconhece a autonomia causal às propriedades emergentes do cérebro, mas não reduz a mente à fisiologia cerebral) (GUTIÉRREZ MARTÍNEZ, 2011, p. 473). O emergentismo forte não conta com muitos adeptos, entretanto não está descartado. Antes da radicalização dos emergentismos (forte ou fraco), a neurociência destaca cinco teses básicas sobre a compreensão da relação mente-cérebro (GUTIÉRREZ MARTÍNEZ, 2011, p. 473):

(1) Tese da irredutibilidade: existem níveis de realidade com propriedades irredutíveis. O mental por mais que emerja do físico não pode reduzir-se a esse nível. (2) Tese ontológica: frente ao dualismo, o emergentismo defende a procedência e a dependência que tem o mental do físico. Só existem identidades físicas (monismo de substância). (3) Tese emergentista: a complexidade física origina a existência de propriedades emergentes (pluralismo de propriedades). (4) Tese realista: as propriedades mentais emergentes são propriedades reais. (5) Tese da clausura causal do físico: tudo o que pode ser causa segue sendo uma entidade física. 
As cinco teses do emergentismo tem consequências enormes. A primeira afirma a impossibilidade de redução da mente ao cérebro, visto ser o cérebro apenas um órgão biológico, enquanto a mente não se reduz às sinapses neurais, ou seja, a mente não significa apenas uma atividade decorrente das sinapses neurais por ser de outra ordem que o cérebro. Essa tese atribui à mente uma origem distinta da clausura corporal. A tese ontológica pretende resolver o dualismo mente-cérebro reduzindo a mente ao cérebro. A procedência neural da mente permitiria compreendêla na dependência do cérebro e do agregado físico de todo o sistema nervoso central (SNC). A terceira tese assemelha-se à primeira, mas não se reduz à mesma, pois afirma a complexidade das propriedades cerebrais. Essa tese complexifica a própria dinâmica cerebral. Enquanto os irredutibilistas atribuem à mente e ao cérebro princípios distintos, os emergentistas atestam a complexidade do cérebro e a inviável redução do mesmo à ordem pura da causalidade biológica. A tese realista também não se reduz a uma variação da tese irredutibilista, porque parte de uma postura radicalmente determinada - a realidade das propriedades mentais. Os realistas não apenas reconhecem a origem distinta das propriedades mentais e cerebrais, mas afirmam a realidade dos atos mentais independentemente do cérebro. Finalmente, a quinta tese tem o escopo mais rígido: "tudo o que pode ser causa segue sendo uma entidade física”. A causa das sinapses neurais são o cérebro e a causalidade dos atos mentais não ultrapassam as causas físicas. Tudo o que responde pelos atos do pensamento - tudo o que causa ou origina um pensamento, não apenas no aspecto neuronal - ainda assim é estritamente físico. Nesse aspecto, não resta nenhuma possibilidade de se compreender a mente sem conectar e reduzi-la imediatamente à fisiologia cerebral.

Essas teses mapeiam e situam os trabalhos das diversas frentes teóricas da neurociência. Nesse sentido, servem como balizas para situarmos as principais interrogações que temos quanto às novidades da neurociência. Se, por um lado, a neurociência parece dessacralizar o cérebro e reduzi-lo a mero agregado biológico, por outro, não consegue explicar toda a complexidade da mente humana. Para alguns estudiosos, a neurociência ainda não explica, enquanto, para outros, a neurociência jamais explicará o funcionamento completo da mente. Nesse sentido, entendemos a distinção entre os neurocientistas que afirmam o problema (suscetível de resolução) da consciência e os demais, que insistem no 
1062 | Veritas | Porto Alegre, v. 63, n. 3, set.-dez. 2018, p. 1058-1072

mistério (incapacidade cognitiva humana). Entre o problema e o mistério, quaestio disputata non data ad philosophos, emergem outras questões que merecem e exigem a consideração de filósofos e teólogos. Sabe-se que a coruja de Minerva, como afirma Hegel, somente levanta voo ao entardecer, por isso o problema e o mistério continuam como quaestio disputata nas mãos dos neurocientistas, enquanto filósofos e teólogos precisam considerar algumas possíveis consequências dos discursos dos dois grupos - problematizadores e misterianos - apenas no âmbito de sua competência. Desprovidos de competência técnica e científica strictu sensu, a filosofia e a teologia (as humanidades) reduzem-se, nesse sentido, à interrogação acerca do sentido, liceidade e alcance das novidades neurocientíficas. Essas interrogações já são demasiadamente agudas para que tenham trabalho por muitas décadas.

\section{[II]}

A busca de autoconhecimento encontra nas ciências não apenas rivais, mas antes, aliadas que mapeiam o terreno em que os humanistas travarão suas batalhas teóricas. Nesse sentido, o voo do pensamento em direção aos problemas da relação mente-cérebro ainda estão apenas começando e prometem povoar por muitas décadas os debates filosóficos e teológicos, pois as consequências das descobertas das ciências provocam diretamente a todos os humanistas sinceros em seus trabalhos. Por isso, uma tentação corriqueira aponta na direção de menosprezar a radicalidade das questões como se a neurociência, por exemplo, reduzisse o escopo de suas descobertas a questões meramente biológicas. Sabe-se que o reverso é mais plausível: cada descoberta neurocientífica implica novas possibilidades e problemas para a autocompreensão do ser humano. Até o presente, com o ralo conhecimento que dispomos do cérebro, podemos elencar seis questões iniciais²: (i) o processo de hominização, (ii)

\footnotetext{
${ }^{2}$ Destacamos seis questões, mas estamos conscientes que omitirmos tantas outras que poderiam integrar-se ao presente artigo, mas omitimo-las por opção metodológica. Entretanto, consideremos a questão referente à nanotecnologia e ao cérebro, apenas a título de exemplo. Se, por um lado, a ciência pesquisa a possibilidade de terapias inteligentes (biohackers) para otimizar os tratamentos de saúde, por outro, ainda não avaliamos axiologicamente os alcances dessas pesquisas. Admitimos como perfeitamente plausíveis o uso de próteses ósseas ou cardiovasculares (como o marcapasso, etc.), mas se pudéssemos acoplar um chip ao cérebro humano e esse passasse a dispor de todas as informações disponíveis na rede mundial de computadores em tempo real, graças aos avanços da nanotecnologia e da neurociência, perguntaríamos: ainda trataríamos como seres humanos (esses novos conhecedores) ou teríamos dado o primeiro e decisivo passo em direção ao pós-humano? Questões com tais méritos estão abertas à discussão e ao estatuto axiológico das ciências humanas que, por sua vez, para ter direito epistêmico
} 
a liberdade, (iii) os limites do conhecimento cerebral e (iv) o conhecimento do cérebro, (v) a relação entre mente-cérebro-mundo e (vi) a "necessidade" do mistério gerada pela dinâmica cerebral. Justamente nesse sentido, uma questão torna-se imperiosa: quais são os alcances da neurociência e suas implicações para as ciências humanas?

(i) O ser humano, como atualmente conhecemos, "não esteve sempre pronto". Ao contrário, entre os hominóides (de trinta e cinco milhões de anos AP) e o Homo Sapiens (há duzentos mil anos AP) há um processo evolutivo demasiado complexo. Desde a introdução da proteína animal na alimentação que transformou o cérebro e o configurou na forma atual, a diversidade de situações e processos é vastíssima. A questão que se coloca aponta na direção da diferença existente entre os primatas (cinquenta e cinco milhões de anos AP) e os hominóides, a saber: o que constitui o ser humano? O bipedismo, o pensamento e a linguagem são os elementos comumente apontados como os traços distintivos, porém o problema é mais radical. Essa tríade aponta a diferença entre os seres animais e o ser animal humano, mas não a explica. As razões dessa diferença não foram equacionadas ainda. Pontuá-las apenas estabelece a distinção, mas a explicação não acompanha a distinção. Ademais, recorrendo à genética, sabe-se que o $\mathrm{ADN}$ das minhocas e dos humanos são idênticos em sessenta por cento, enquanto a diferença entre os humanos e chimpanzés é muito menor: noventa e oito por cento do ADN humano e chimpanzé é igual. A diferença de apenas dois por cento explica o bipedismo, o pensamento e a linguagem? O que faz esse animal bípede, pensante e falante ser, propriamente, humano? Quais são as razões da hominização? Se tomarmos apenas o critério genético, o humano difere do chimpanzé por uma pequena percentagem, mas essa diferença explica toda a complexidade do cérebro, da vida, da civilização e da tecnologia humana? Se consideramos a tese da irredutibilidade, podemos afirmar a existência de propriedades humanas irredutíveis ao mero nível da fisiologia cerebral. Se partirmos da tese da clausura causal do físico, teremos que admitir que apenas dois por cento de diferença do ADN justificam a diferença entre chimpanzés e humanos: bipedismo, pensamento, linguagem, civilização, tecnologia, etc. Eis a questão: o que

ao diálogo científico, precisam conhecer os pressupostos científicos e desenvolverem críticas internas aos seus próprios pressupostos epistêmicos em vistas de alcançarem um diálogo profícuo com as ciências, sobretudo a neurociência. 
1064 | Veritas | Porto Alegre, v. 63, n. 3, set.-dez. 2018, p. 1058-1072

torna o ser propriamente humano frente a todos os demais animais? Como se explica o processo de hominização do ponto de vista meramente biológico? Para biólogos e neurocientistas como Dawkins (2007, p. 215), existe apenas um imperativo darwinista evolutivo e seletista como responsável para explicar a complexidade da biologia humana. Para Monod (2006, p. 137), a explicação do ser humano decorre de uma estrutura teleonômica guiada por uma necessidade interna e justificada pelo mero acaso. Entretanto, para Stein (2010, p. 189), a hominização explica-se apenas pelo salto antropológico irredutível à clausura causal do físico. A primeira questão, portanto, refere-se ao processo pelo qual somos o que somos, isto é, o processo de hominização que não se explica facilmente nem pela genética nem pela neurociência. A investigação aponta a necessidade de pensar e justificar crítica e cientificamente os elos entre primatas, hominóides e Homo Sapiens. O que torna o animal que ora somos, um ser propriamente humano? Quais são as razões que explicam a irrupção do ser humano - a hominização - no mundo sem atribui-la simplesmente ao acaso?

(ii) A segunda questão aberta é tão radical quanto a primeira: eis, pois, a liberdade. Se admitimos que o cérebro constitui-se por um processo teleonômico auto-organizador que permite a passagem do caos ao cosmos mental, isto é, das simples sinapses neurais ao surgimento da mente - do cérebro à mente - então, compreendemos os processos neurais como fonte constitutiva da mente. Se a mente resulta do cérebro e ele funciona por descargas elétricas que estabelecem as sinapses entre os milhões de neurônios, então a mente nasce de um processo puramente biológico ou cerebral - neuronal - e, nesse sentido, assenta-se a tese ontológica: "existem somente identidades físicas (monismo de substância)". Nesse caso, a mente não é outra coisa que o pálido resultado das sinapses neurais e, se entendermos como funcionam essas sinapses, entenderemos o funcionamento do cérebro e, por adição, a operação da mente. O monismo de substância instaura a possibilidade de considerarmos o cérebro como o detentor e o limite da mente e, consequentemente, sabendo que o cérebro não é outra coisa que um agregado biológico teleonômico, assim que se conhecer esse agregado, seremos capazes de conhecer a mente de qualquer ser humano. Os defensores da tese ontológica acreditam a possibilidade de um conhecimento exaustivo do cérebro em algum momento da evolução neurocientífica e, portanto, da determinação 
completa da mente humana. Alguns neurocientistas justificam essa possibilidade através da teoria das cordas constitutivas dos quasares, pois o momento do conhecimento das cordas e a compreensão da lógica de seu funcionamento coincide naturalmente com a determinação da lógica cerebral. Decodificada a lógica cerebral, compreende-se todo o funcionamento da mente. Nesse sentido, tal como o ADN permite estabelecer o mapa genético, o conhecimento das cordas e, por tabela, dos neurônios e das sinapses, permitiria conhecer a mente e toda sua capacidade produtiva, a saber: todos os pensamentos. Assim, se soubermos todos os pensamentos possíveis de uma pessoa, estaremos de posse das possibilidades de suas escolhas e, nesse sentido, a liberdade humana seria reduzida à mera lógica da probabilidade: uma opção entre $n$ possibilidades. Essa discussão é, tecnicamente, desenvolvida por John Searle, mas ele duvida que a possibilidade de compreensão da mente coincida com o assentimento racional do fim da liberdade. Searle questiona (2007, p. 71): "se demonstrássemos que a tomada de decisão livre e racional não existe, o senhor, racional e livremente, tomaria a decisão de aceitar o fato de que tais decisões não existem?”, vale dizer: se conscientemente soubermos que todas as nossas escolhas estão previamente determinadas pelas sinapses neurais (vale dizer: qualquer escolha que julgamos fazer, resulta simplesmente de uma prévia determinação operativa da simples mecânica neuronal) ainda assim estaremos dispostos a assentir voluntariamente que não somos livres? Searle interroga a capacidade humana de assentir conscientemente reconhecendo o fim da liberdade frente ao conhecimento dos processos neuronais instaurando, nesse caso, uma espécie de paradoxo entre liberdade e conhecimento neuronal.

(iii) As questões terceira e quarta estão ligadas, pois tratam do conhecimento do cérebro no sentido subjetivo e objetivo, isto é, o cérebro como sujeito e como objeto do conhecimento. Enquanto sujeito do conhecimento, a neurociência conduz à investigação sobre os limites do conhecimento cerebral. A capacidade e possibilidade do conhecimento desenvolvido pelo cérebro humano não parece, em certo sentido, a única e exclusiva fonte de conhecimento possível. O conhecimento cerebral depende da fisiologia neurológica e, nesse caso, um acidente ou alguma deficiência põem a perder a capacidade cognitiva do cérebro ou mesmo altera suas reações diante de algumas situações. Como aparelho biológico 
1066 | Veritas | Porto Alegre, v. 63, n. 3, set.-dez. 2018, p. 1058-1072

teleonômico, o cérebro funciona dinamicamente na passagem do caos ao cosmos: a natureza como a realidade primeira acessada pelo cérebro não tem uma ordem pré-estabelecida, nesse sentido, a natureza é caótica. Tal qual o mito bíblico, o humano é que nomeia a natureza, transformando-a em mundo habitável. A taxonomia da natureza provem da atividade humana, enquanto ser capaz de nomear (ónoma) e normalizar, legislar sobre o mundo (instituir nomós). Sem a presença do cérebro ordenador, a natureza não se torna mundo, não há mundo sem o ser humano. Essa questão está presente no mito bíblico e nos Conceitos fundamentais da metafísica: mundo, finitude, solidão de Martin Heidegger (2003, § 45-48 e STEIN, 2003, p. 16): "a pedra é sem mundo, o animal é pobre em mundo e o homem é formador de mundo.” É exatamente nesse sentido que entendemos o funcionamento do cérebro: a passagem do caos (o dado natural sem forma inicial: a natureza não classificada ou sem a taxonomia humana) ao cosmos (a natureza classificada, identificada e nomeada pela ação humana). Com isso, entende-se a capacidade de conhecimento cerebral enquanto potência ordenadora ou configuradora do mundo. Porém, o mundo se reduz àquilo que a humanidade conhece? Essa questão não está de todo clara. Podemos entendê-la pelo exemplo de Montaigne (2016, I, 31): a expansão mercantil da Península Ibérica nos séculos quinze e dezesseis permitiu, segundo a historiografia imperial, a descoberta de novas terras que, supostamente, eram habitadas por "seres humanos" que foram tratados como "tábulas rasas". Entretanto, Montaigne questionava se aqueles que os europeus duvidavam ser "humanos" não seriam, de fato, os "irmãos desconhecidos até o presente". Para alguns europeus, os habitantes do Novo Mundo eram bestas, para outros, irmãos da grande família da humanidade. Nesse sentido, a questão posta pelos limites do conhecimento cerebral é a seguinte: o conhecimento possível existente no mundo reduz-se ao que conhecemos racionalmente? Se assim o fosse, os europeus não teriam buscado novas terras, nesse sentido, há, não apenas na dimensão extensional, mas intencional, um largo horizonte desconhecido da capacidade cerebral. Então, seria possível pressupor um conhecimento cerebral ilimitado?

(iv) Consideremos agora o aspecto objetivo do conhecimento cerebral: a possibilidade do conhecimento do cérebro. A fisiologia cerebral não motiva a pretensão de conhecimento, porque, aproximadamente, trezentos milhões de neurônios não parecem uma empreitada fácil de ser 
conhecida quando ainda não conhecemos nenhum neurônio em todas as suas possibilidades. Esses milhões de neurônios multiplicam-se por, aproximadamente, dez milhões de sinapses possíveis para cada neurônio. Quantos neurocientistas seriam necessários para compreender a dinâmica cerebral? Esse problema pode ser afrontado de duas formas: pela tese ontológica afirmando o monismo de substância e reduzindo a mente ao cérebro ou pela tese realista admitindo as realidades mentais como propriedades reais. O monismo de substância obstaculiza a compreensão da mente fazendo-a depender exclusivamente da dinâmica fisiológica do cérebro. Necessário se faz, nesse caso, "apenas" conhecer o cérebro e suas sinapses e teríamos domínio completo da mente humana. Porém, o conhecimento dos milhões de neurônios e suas respectivas sinapses não parece de todo simples e factível a curto prazo. Uma via de aproximação desse conhecimento seria o conhecimento pleno da teoria das cordas, mas essa pesquisa ainda não logra êxito suficiente. Além disso, algumas experiências da neurociência são pouco animadoras, como as "experiências do rato e da barata" estudados na Universidade São José na Califórnia (KAKU, 2011, p. 122³). Se o exemplo é coeso, então o alcance da pesquisa neurocientífica está muito aquém da possibilidade de determinação da lógica neuronal. Os limites do conhecimento do cérebro seriam tanto subjetivo (parece pouco provável que o conhecimento cerebral seja todo o conhecimento possível da realidade) quanto objetivo (conhecer a fisiologia e capacidade cerebral ainda é um horizonte distante da realidade). Nesse sentido, a pretensão de determinação do cérebro pela neurociência, no status quaestiones da pesquisa, está distante da meta e o cérebro permanece um objeto quase inacessível ao conhecimento humano. Se esse é o caso, a questão que se coloca é a seguinte: o conhecimento do cérebro é um problema ou um mistério? Se admitirmos o problema, continuamos a crer na possibilidade de uma resolução em algum tempo. Se admitirmos o mistério, descremos o conhecimento do cérebro pela pesquisa neurocientífica. Se o conhecimento cerebral é um problema, em algum momento deixará de ser e teremos acesso à compreensão plena do

\footnotetext{
${ }^{3}$ KAKU, 2011, p. 122: "o que me interessava era o facto de o Blue Gene estar a simular o processo mental de um cérebro de rato, com cerca de 2 milhões de neurónios (em comparação com os 100 mil milhões de neurónios de um cérebro humano). [...] (Isto não quer dizer que o Blue Gene consiga simular o comportamento de um rato. Neste momento, os cientistas mal conseguem simular o de uma barata. O que quero dizer é que o Blue Gene pode simular o disparo de neurónios existentes num rato, e não o comportamento desse animal.)”
} 
seu funcionamento e, por consequência, da mente. A questão que se coloca é a existência da liberdade da vontade. Admitir o mistério do cérebro pode significar uma "solução comodista" e consequente desinteresse pela pesquisa. Mas os resultados e avanços da neurociência no mapeamento do cérebro são inegáveis. Então, nós consideraremos o cérebro como problema ou mistério?

(v) Outra questão inesquecível refere-se à relação mente-cérebromundo. Há quem diga que o cérebro não pensa na tina. O legista responsável pelo laudo de Albert Einstein confessa ter retirado do crânio do gênio a massa neurológica responsável pelas maiores descobertas físicas recentes (NEFFE, 2012, p. 9). Durante muitos anos em suas pesquisas e mudanças levou consigo o agregado fisiológico responsável pela teoria da relatividade, mas segundo análises e estudos fisiológicos, nenhuma diferença foi registrada. Nesse sentido, nem a fisiologia cerebral nem o agregado fisiológico desconectados do corpo e do mundo conseguem pensar. Por um lado, isso significa que a forma fisiológica não determina o resultado do pensamento. Por outro, o cérebro somente tem capacidade de pensar se, e somente se, estiver conectado ao corpo e ao mundo. A consequência dessa afirmação é grande, pois, no presente caso, estabelecer uma teoria do conhecimento cerebral exige considerar não apenas os neurônios e suas sinapses, mas também as relações bilaterais do cérebro com o corpo e o mundo. Esse é o ponto em que Hilary Putnam coloca o status quaestiones das interrogações neurocientíficas. Putnam (2002, p. 187s) amplia e complexifica bastante a tarefa da neurociência, porque estabelece novas necessidades para a compreensão do todo, a saber: (a) a relação mente-cérebro, (b) a relação cérebro-corpo, (c) a relação cérebro-mundo e (d) a relação cérebro-corpo-mundo. Essas relações originam-se da tripla corda: mente, corpo e mundo. A teoria do conhecimento neurocientífica não se reduz aos limites do conhecimento subjetivo e objetivo do cérebro, pois, no aspecto subjetivo, o cérebro somente conhece situado no corpo e no mundo e, no aspecto objetivo, o conhecimento do cérebro exige o conhecimento também do corpo e do mundo, porque o cérebro não pensa na tina. A capacidade cognitiva cerebral é sempre situacional, por isso sua situação - corporal e mundana - não podem ser desconsideradas no estabelecimento das condições de possiblidade do conhecimento. As quatro relações básicas enumeradas apontam em direção à crescente impossibilidade de uma solução 
minimalista, ou seja, afirmar o conhecimento da fisiologia cerebral como suficiente para o conhecimento dos limites da racionalidade humana não é suficiente. A compreensão do cérebro exige uma resposta antiminimalista, ou seja, uma busca de compreensão do cérebro e de suas relações imediatas e insuperáveis, porque o cérebro é uma fisiologia complexa situada corporal e mundanamente. Excluir essa complexidade e sua situação limita e obstrui a possibilidade de uma resolução adequada e sensata da questão. Nesse caso, a compreensão de Putnam amplia a complexidade das respostas neurocientíficas. $\mathrm{O}$ contrário equivaleria à admissão de certo minimalismo reduzindo tudo à capacidade do cérebro. Por isso, destaca-se a questão: a mente, como resultado do cérebro, existiria independente do corpo e fora do mundo?

(vi) $\mathrm{O}$ último aspecto que consideramos importante refere-se à "necessidade do mistério" gerada pela dinâmica cerebral, ou melhor, a biologia da transcendência. As teses da irredutibilidade e da emergência afirmam a existência de níveis distintos de realidade e o pluralismo de propriedades permite a compreensão do lugar de Deus dentro da neurociência, constituindo as bases de uma possível neuroteologia. A relação entre neurociência e teologia estabelece-se graças à compreensão adequada das duas dimensões fundamentais da realidade: o mundo e o si mesmo. Essas grandezas são irredutíveis, ao mesmo tempo que, as experiências místicas do sujeito são tão reais quanto as experiências mundanas (NEWBERG et alii, 2015, p. 152 e 16o). Nesse sentido, a sabedoria dos místicos encontra apoio na neurociência atual: "na Existência unitária absoluta, o si se funda no outro. O espírito e a matéria são uma só e mesma coisa" (NEWBERG et alii, 2015, p. 164). A dinâmica cerebral durante as experiências místicas registradas pela neurociência não deixa dúvida acerca da conciliação entre ciência e religião. Outrora, acreditava-se exclusivamente que "tudo o que é real pode ser verificado por uma medida científica e, pois, o que não pode ser verificado pela ciência não é realmente real" (NEWBERG et alii, 2015, p. 178), mas a compreensão científica encontra-se, atualmente, alargada e já se sabe que essa hipótese fundadora da ciência é mitológica. Reconhece-se que a ciência não prova a existência de Deus, mas apresenta evidências suficientes acerca da "possibilidade plausível e mesmo provável" da sua existência. A Existência unitária absoluta é fartamente reconhecida pelas leituras neurológicas das atividades cerebrais nos místicos e a intensidade 
da experiência detectada pelos eletrodos não deixa dúvidas quanto à sua realidade. "A realidade da Existência unitária absoluta não é uma prova definitiva que um Deus superior existe, mas ela é um sólido argumento para a ideia que a existência humana é bem mais que uma existência puramente material” (NEWBERG et alii, 2015, p. 179). A irredutibilidade física e o pluralismo de propriedades permite um redimensionamento do discurso humanista frente à neurociência. Nesse sentido, ela permite a compreensão científica da realidade da experiência mística, embora não indique senão a Existência unitária absoluta. Assim sendo, a neurociência reaproxima ciência e teologia em uma neuroteologia, entretanto não determina nem indica nada acerca do conteúdo dessa Existência. Cabe, portanto, às humanidades entenderem e explicarem a necessidade do mistério, continuamente, gerada pela mecânica e arquitetônica cerebral. A região parietal do cérebro através das funções causais e binárias replica continuamente os mitos, pois o cérebro parece ter uma verdadeira necessidade dos mesmos. O que há, portanto, au-delà de l'essence et audelà de la realité que é constitutivo e fundador da mecânica cerebral?

Essas questões são apenas algumas das perspectivas básicas e possíveis da relação entre as ciências humanas e a neurociência. A consideração das possibilidades e dos alcances da ciência não feitas pela própria ciência, pois, nesse sentido, a ciência não pensa, como reafirmou continuamente Heidegger. O juízo de valor acerca dos resultados e consequências da ciência provém naturalmente de uma instância exterior ou distinta à ciência, no caso, das ciências humanas. Não que as ciências humanas sejam o tribunal da ciência, mas a valoração epistêmica está continuamente associada à dinâmica interna das ciências humanas. Cabe, portanto, estabelecer a relação e dialogar com os avanços científicos em vistas de entender o alcance da neurociência e suas implicações para as ciências humanas. Nesse sentido, o diálogo entre elas e a neurociência ou a ciência em geral, implica alguns pressupostos. A afirmação heideggeriana - a ciência não pensa - não convém sem admitida sem considerações, pois a ciência não tem a preocupação axiológica em primeiro plano. A ciência prima pela funcionalidade e operatividade em vistas de responder demandas sociais através da produção de bens ou fármacos suficientes para a sociedade. Enquanto as ciências humanas priorizam a axiologia epistemológica interrogando o sentido, a liceidade e o alcance dos avanços científicos. Assim sendo, para estabelecermos um 
diálogo profícuo com as ciências, precisamos priorizar (i) o compromisso epistêmico que implica um conhecimento suficiente dos elementos fundamentais da ciência para estabelecermos um diálogo sincero; (ii) a honestidade metodológica - não partir do pressuposto de que as ciências humanas estejam acima ou tenham um valor superior às ciências naturais, ao contrário, ambas estão em busca de respostas para os mesmos problemas humanos, porém com pressupostos, métodos e interesses distintos, o que não torna uma ou outra melhor ou pior que seu páreo; (iii) a democratização do conhecimento implica um compromisso de honestidade e responsabilidade social em vistas de tornar todo o conhecimento alcançado disponível para a sociedade e, nesse ponto, inclua-se o espaço da reflexão axiológica acerca dos limites e responsabilidades do saber; e (iv) a responsabilidade política dos enunciados - desde que Habermas explicitou a relação entre conhecimento e interesse e Bacon relacionou saber e poder no terceiro aforisma do Novum Organom, não se crê mais a neutralidade ética do conhecimento nem da ciência em geral, por isso todo enunciado científico traz consigo a responsabilidade pelos enunciados e implicam, simultaneamente, consequências políticas do conhecimento. Nesse sentido, tanto as ciências humanas precisam deixar-se questionar em seus pressupostos e verdades provenientes dos avanços das ciências naturais quanto essas precisam abrir-se ao diálogo e às considerações axiológicas acerca do valor e das consequências dos enunciados científicos.

\section{Bibliografia}

CUNHA, E. Como nos tornámos humanos. Coimbra: Imprensa da Universidade de Coimbra, 2010. (Estado da Arte 4).

DAWKINS, R. Deus, um delírio. $7^{\mathrm{a}}$ reimpressão. Tradução de F. Ravagnani. São Paulo: Companhia das Letras, 2007.

GUTIÉRREZ MARTÍNEZ, A. La conciencia: ¿problema o misterio? In: Studium. Revista cuatrimestral de filosofía y teología, vol. LI, Fasc. 3 (2011), p. 469-486. Madrid: Institutos Pontificios de Filosofía y Teología.

HEIDEGGER, M. Conceitos fundamentais da metafísica: mundo, finitude, solidão. Tradução de M. A. Casanova. Rio de Janeiro: Forense Universitária, 2003. 
1072 | Veritas | Porto Alegre, v. 63, n. 3, set.-dez. 2018, p. 1058-1072

KAKU, M. A física do futuro: como a ciência moldará o mundo nos próximos cem anos. Tradução de M. Carvalho e J. C. S. Duarte. Lisboa: Bizâncio, 2011.

LLAMAS, B. et alii. Ancient mitochondrial DNA provides high-resolution time scale of the peopling of the Americas. In: Science Advances, vol. 2, $\mathrm{n}^{0} 4$ (2016). DOI: 10.1126/scadv.1501385 http://advances.sciencemag.org/content/2/4/e1501385. full.pdf+html Acesso em 20.05.2016.

MONOD, J. O acaso e a necessidade: ensaio sobre a filosofia natural da biologia moderna. $6^{\text {a }}$ edição. Tradução de B. Palma e P. P. S. Madureira. Petrópolis: Vozes, 2006.

MONTAIGNE, M. Ensaios. Tradução de S. Milliet. São Paulo: 34, 2016.

NEFFE, J. Einstein: uma biografia. Tradução de I. A. Lohbauer. Barueri: Novo Século, 2012.

NEWBERG, A., D’AQUILI, E. \& RAUSE, V. 2015. Pourquoi «Dieu » ne disparaîtra pas : quand la science explique la religion. $2^{\mathrm{e}}$ édition. Traduit de l'anglais par K. D. Robert. France : Sully, 2015.

PUTNAM, H. A tripla corda: mente, corpo e mundo. Tradução de L. Teopisto. Lisboa: Instituto Piaget, 2002.

SEARLE, J. R. Liberdade e neurobiologia: reflexões sobre o livre-arbitrio, a linguagem e o poder político. Tradução de C. M. E. Morel. São Paulo: Unesp, 2007.

STEIN, E. Nas proximidades da antropologia: ensaios e conferências filosóficas. Ijuí: Unijuí, 2003.

STEIN, E. Antropologia filosófica: questões epistemológicas. $2^{\text {a }}$ edição revisada. Ijuí: Unijuí, 2010.

STRAUSS, A. et alii. The Oldest Case of Decapitation in the New World (Lapa do Santo, East-Central Brazil). In: Plos One (2015). DOI: 10.1371/journal.pone.0137456, september 23, 2015. http://journals.plos.org/plosone/article?id=10.1371/ journal.pone.0137456 Acesso em 23.05.2016. 